\title{
Imitation by price and quantity setting firms in a differentiated market
}

Citation for published version (APA):

Khan, A., \& Peeters, R. J. A. P. (2013). Imitation by price and quantity setting firms in a differentiated market. Maastricht University, Graduate School of Business and Economics. GSBE Research Memoranda No. 022 https://doi.org/10.26481/umagsb.2013022

Document status and date:

Published: 01/01/2013

DOI:

10.26481/umagsb.2013022

Document Version:

Publisher's PDF, also known as Version of record

\section{Please check the document version of this publication:}

- A submitted manuscript is the version of the article upon submission and before peer-review. There can be important differences between the submitted version and the official published version of record.

People interested in the research are advised to contact the author for the final version of the publication, or visit the DOI to the publisher's website.

- The final author version and the galley proof are versions of the publication after peer review.

- The final published version features the final layout of the paper including the volume, issue and page numbers.

Link to publication

\footnotetext{
General rights rights.

- You may freely distribute the URL identifying the publication in the public portal. please follow below link for the End User Agreement:

www.umlib.nl/taverne-license

Take down policy

If you believe that this document breaches copyright please contact us at:

repository@maastrichtuniversity.nl

providing details and we will investigate your claim.
}

Copyright and moral rights for the publications made accessible in the public portal are retained by the authors and/or other copyright owners and it is a condition of accessing publications that users recognise and abide by the legal requirements associated with these

- Users may download and print one copy of any publication from the public portal for the purpose of private study or research.

- You may not further distribute the material or use it for any profit-making activity or commercial gain

If the publication is distributed under the terms of Article $25 \mathrm{fa}$ of the Dutch Copyright Act, indicated by the "Taverne" license above, 


\section{Maastricht University}

Abhimanyu Khan, Ronald Peeters

I mitation by price and quantity setting firms in a differentiated market

$\mathrm{RM} / 13 / 022$

\section{GSBE}

Maastricht University School of Business and Economics

Graduate School of Business and Economics

P.O Box 616

NL- 6200 MD Maastricht

The Netherlands 


\title{
Imitation by price and quantity setting firms in a differentiated market*
}

\author{
Abhimanyu Khan ${ }^{\dagger} \quad$ Ronald Peeters ${ }^{\ddagger}$
}

May 6, 2013

\begin{abstract}
We study the evolution of imitation behaviour in a differentiated market where firms are located equidistantly on a (Salop) circle. Firms choose price and quantity simultaneously, leaving open the possibility for non-market clearing outcomes. The strategy of the most successful firm is imitated. Behaviour in the stochastically stable outcome depends on the level of market differentiation and corresponds exactly with the Nash equilibrium of the underlying game. For high level of differentiation, firms end up at the monopoly outcome. For intermediate level of differentiation, they gravitate to a "mutually nonaggressive" outcome where price is higher than the monopoly price. For low level of differentiation, firms price at a mark-up above the marginal cost. Market clearing always results endogenously.
\end{abstract}

JEL Classification: C72, C73, D21, D43, L11, L13.

Keywords: oligopoly; imitation; evolution.

${ }^{*}$ We would like to thank Jean-Jacques Herings for useful comments and suggestions and the Netherlands Organisation for Scientific Research for financial support.

${ }^{\dagger}$ Department of Economics, Maastricht University. E-mail: a.khan@maastrichtuniversity.nl

${ }^{\ddagger}$ Department of Economics, Maastricht University. E-mail: r.peeters@maastrichtuniversity.nl 


\section{Introduction}

In an influential paper, Alchian (1950) discusses an alternate economic approach emphasising relative performance over absolute performance. In the context of firm behaviour and industrial organisation, it suggests that firms might evaluate themselves in terms of relative profit, rather than absolute profit. We adopt a similar approach by assuming that a firm does not necessarily choose the profit-maximising strategy, owing perhaps to lack of relevant information or some form of bounded rationality. However, it observes other firms, which allows it to compare its performance with those who are similarly placed. The consideration of relative profit might drive it to adopt simple heuristics such as imitation of the most successful firm; adoption of industry best practises may be an example of this. In fact, Huck et al. (1999), Huck et al. (2000), Offerman et al. (2002) and Apesteguia et al. (2007) find some experimental evidence of a firm imitating the more successful firm once feedback on strategies and profits is explicitly provided.

In the context of homogeneous markets, Vega-Redondo (1997) develops an evolutionary Cournot model, where firms choose quantities, and the total quantity produced determines the market price. The quantity-choice of each firm and its profit is observable to all. A typical firm (almost always) imitates the firm that received the highest profit, while occasionally choosing a random quantity. The stochastically stable outcome of this process is the Walrasian equilibrium. On the other hand, Alós-Ferrer et al. (2000) study an evolutionary Bertrand model in a homogeneous market. Firms, which have increasing marginal cost, choose prices and the lowest price-setters win the market, with the market demand function dictating the total quantity to be produced. Again, the strategy of each firm and the corresponding profit is observable and a firm (almost always) imitates the most successful firm. In this case, the stochastically stable outcome is given by a strict subset of the set of Nash equilibria.

Here, we study the evolution of imitative behaviour in a horizontally differentiated market. Firms are equidistantly located on a circle of unit circumference, while consumers are located uniformly along the circumference. ${ }^{1}$ The extent of differentiation is reflected in the transportation cost that consumers incur when they travel to a firm to acquire the good. Firms choose both price and quantity, and market-clearing is not assumed a priori. ${ }^{2}$ This is descriptive of situations where production may be in advance (as in a Cournot model as opposed to a Bertrand model, where it is on-demand) and yet firms have the independence

\footnotetext{
${ }^{1}$ While the assumption of equidistantly located firms is made merely to specify the demand structure, it is interesting to note that Hehenkemp and Wambach (2010) comment that this would also be the stochastically stable outcome of an evolutionary model where firms choose their location on the Salop circle.

${ }^{2}$ Herings (1997) and Alós-Ferrer and Kirchsteiger (2010) show that it is possible for non-clearing markets institutions to evolve.
} 
to choose price (as in a Bertrand model but unlike a Cournot model).

The firms operate in an informationally sparse environment - they are only aware of their own cost and the presence of other firms. In particular, they need not know that they are in a differentiated market, the consumers' valuation of the product or the consumers' preferences between the firms. The strategy of a firm and its profit is observable. The informational constraints may compel a firm to use rules of thumb which, in this case, are specified by imitation of the strategy of the firm with the highest profit. Occasionally a firm may experiment with other strategies, and our interest lies in the stochastically stable outcome, which is the outcome one would expect to emerge over time from the process of imitation as the tendency to experiment goes to zero. ${ }^{3}$

The results indicate that the stochastically stable outcome of this process of imitation coincides with the (unique symmetric) Nash equilibrium of the underlying game, and it depends on the level of market differentiation. For high levels of differentiation, each firm charges a "monopoly" price and chooses to produce the demand that it faces at this price. Of course, the "monopoly" price that each firm chooses is independent of the number of firms and the level of differentiation. For intermediate levels of differentiation, each firm chooses a "mutually non-aggressive" price and produces the corresponding demand. Counter-intuitively, in this case, an increase in the number of firms increases the price that a firm charges (ceteris paribus); additionally, an increase in the level of differentiation decreases the price charged by a firm (ceteris paribus). ${ }^{4}$ The implication of this is that more competition may actually increase prices while greater market differentiation may reduce them. Finally, for low levels of differentiation, each firm charges a mark-up over the marginal cost, where the mark-up varies positively with the level of product differentiation and negatively with the number of firms; the quantity chosen by each firm equals the demand that it faces. The stochastically stable states are all endogenously market-clearing.

It is interesting to see the coincidence of the outcome of this "low-rationality" process with the Nash equilibrium as it is often observed that an imitation protocol leads to spiteful behaviour that is detrimental for all involved. Because of the importance accorded to relative payoffs (or in this case, relative profit), a firm may be driven to adopt a strategy that while reducing its own payoff, reduces that of its rivals to a larger degree. Vega-Redondo (1997), where quantity-choosing firms end up in the Walrasian outcome (which is not a Nash equilibrium outcome) with imitation, is an illustration of this. In spite of this spite-incentive,

\footnotetext{
${ }^{3}$ Khan and Peeters (2011) study an evolutionary model where duopolists located at the ends of a Hotelling line choose price and quantity and imitate the more successful firm. We use a similar model in this paper.

${ }^{4}$ As mentioned, this is also a feature of the Nash equilibium, and is a point that has, to the best of our belief, not been made in the literature.
} 
we find that the Nash outcomes are expected to emerge in the long-run and we present the intuition for this at a later stage.

The paper is structured as follows. In section 2 we present the model. Section 3 contains the results. We begin by characterising the Nash equilibrium of the situation and then demonstrate the stochastically stable outcome of the imitation process. We provide the intuition for the coincidence of the two solution concepts mentioned above and comment on its qualitative features. Section 4 discusses some aspects of the results, such as the amount of observability that is required to drive the imitation process. Section 5 concludes. Almost all proofs are contained in the Appendix.

\section{Model}

Firms are equidistantly located on a Salop circle of unit circumference. Let the number of firms be denoted by $n$, and we assume that there are at least four of them, i.e. $n \geq 4$. The distance between a firm and its nearest neighbour (on either side) is equal to $\frac{1}{n}$. We index a particular firm and its location as firm 0 and point 0 respectively. The other firms are indexed clockwise from firm 0 , so that firm 1 is at the point $\frac{1}{n}$ and firm $k$ is located at the point $\frac{k}{n}$, where $k$ is an integer between 0 and $n-1$. Firms independently and simultaneously choose price and quantity. ${ }^{5}$

Consumers are uniformly distributed on the circumference of the circle and they are indexed by their clockwise distance from firm 0 . The common intrinsic utility attributed to a unit of the good is denoted by $\beta$. They observe the prices posted by the firms, based on which they decide to either purchase the good or to abstain from it. Each consumer acquires at most one unit of the good. On making a purchase, the consumer incurs a linear transportation cost of $\tau$ per unit distance to the firm purchased from. The distance between a consumer and a firm or between two firms always refers to the closest distance; due to the circular structure, there exists a clockwise distance and a counter-clockwise distance and whenever we refer to the distance, we imply the lesser of the two. The net utility of a purchase is the gross utility, $\beta$, less the price and transportation cost to the chosen firm. The reservation utility on abstinence from purchase is normalised to 0. A typical consumer maximises net utility. Hence, they buy from a firm only if the net utility from purchase is at least 0 ; and in the case that they make a purchase, they buy from the firm that would leave them with the highest

\footnotetext{
${ }^{5}$ We assume a discrete strategy space by supposing the existence of a price grid and a quantity grid. In particular, we assume that all prominent prices and quantities (that is, those stated in the propositions and needed to complete the proofs) are contained in these grids. Firms can choose any price and quantity from the respective grid.
} 
net utility. ${ }^{6}$

We assume that, for a consumer, the price chosen by a firm is more salient and observable than the quantity chosen by it, and so the decision of a consumer is based entirely on the price. It is possible that the consumer is not able to acquire the good from the chosen firm due to insufficient quantity produced. We abstract away from the issue of spillover-demand, i.e. we ignore the possibility of a consumer, on not being able to make a purchase from the chosen firm, traveling to another firm that has excess supply. This, in principle, might lead to a situation where one firm has excess demand while another firm has excess supply. An analysis which incorporates the feature of spillover-demand would necessarily have to come with additional assumptions on how a firm facing excess demand rations or distributes the goods amongst consumers who line-up in front of it. To elaborate briefly, it is possible that a consumer prefers acquiring a good at more than one firm to not acquiring one at all while there might be another consumer who would prefer to acquire the good only from a specific firm. The possibility of spillover demand arises only if both these consumers prefer the same quantity-constrained firm and the second consumer gets served. To examine this, there needs to be an assumption on which consumer acquires the good in case their preferred firm faces excess demand. Even though it might be interesting to study this possibility, we do not pursue it in this paper.

The demand $\left(d_{i}\right)$ faced by firm $i$ may be different from the quantity $\left(q_{i}\right)$ produced by it. The amount sold by the firm $\left(s_{i}\right)$ is defined to be the minimum of $q_{i}$ and $d_{i}$. We assume that each firm has a constant cost of production of $c$ per unit and that $\beta>c$ such that there is room for efficient trade. A firm knows its own marginal cost and does not consider choosing prices below it. The profit of firm $i$ when it chooses a price of $p_{i}$ and produces $q_{i}$ is:

$$
\pi_{i}=p_{i} \cdot s_{i}-c \cdot q_{i}
$$

The demand that a firms faces depends on the price that it chooses and the price chosen by the other firms; it comes from the set of consumers who receive the highest net utility from it, subject to the net utility being at least equal to 0 . First of all, if the price that firm $i$ chooses is higher than the gross utility, $\beta$, then it faces zero demand as any consumer buying from it would receive a net utility lower than the reservation utility of not buying. Secondly, firm $i$ also faces zero demand if the closest firm (and so a distance of $\frac{1}{n}$ away from it) chooses a price less than $p_{i}-\frac{\tau}{n}$; and more generally, it faces zero demand if a firm that is at a distance of $\frac{k}{n}$

\footnotetext{
${ }^{6}$ When the maximum net utility that a consumer receives on purchase is exactly equal to 0 , we assume the good is purchased. If a consumer receives the maximum net utility (of at least zero) from more than one firm, we assume that the consumer chooses randomly amongst the firms in contention and there is positive probability of purchase from each of these firms.
} 
away from it chooses a price below $p_{i}-k \frac{\tau}{n}$. In this case, a consumer never gets the highest net utility from firm $i$; given the prices, even the consumer closest to firm $i$ would prefer to incur a higher transportation cost and buy from some other firm.

Having outlined the conditions under which a firm faces zero demand, we now discuss the conditions under which each firm faces positive demand. This implies that all prices are less than $\beta$ and are such that a firm at a distance of $\frac{k}{n}$ from firm $i$ chooses a price above $p_{i}-k \frac{\tau}{n}$, and this is true for all relevant values of $k$ and $i=0,1, \ldots, n-1$. We focus on the demand of firm 0 from the clockwise direction; the demand that it faces from the counter-clockwise directions may be similarly derived. Let firm 0 and firm 1 choose prices $p_{0}$ and $p_{1}$ respectively. As mentioned above, $\left|p_{1}-p_{0}\right|<\frac{\tau}{n}$ and, for a cleaner exposition, we assume (only for this paragraph) that the price chosen by the other firms is such that the consumers located in between firm 0 and firm 1 buy (if at all) only from one of these two firms. Then, two situations arise with respect to the $\frac{1}{n}$ mass of such consumers. If $p_{0}>2 \beta-p_{1}-\frac{\tau}{n}$, then the two firms do not compete for the marginal consumer; the demand that firm 0 faces from consumers who lie between the two firms equals $\frac{\beta-p_{0}}{\tau}$ (while firm 1 faces a demand of $\frac{\beta-p_{1}}{\tau}$ ). ${ }^{7}$ This is because the consumer who is at a distance of $\frac{\beta-p_{0}}{\tau}$ from firm 0 receives exactly zero utility from firm 0 but receives negative utility from all other firms and so this consumer desires to buy from firm 0 . A consumer who is even slightly more distant from firm 0 would receive negative utility and so, does not demand from firm 0 . On the other hand, if $p_{0} \leq 2 \beta-p_{1}-\frac{\tau}{n}$, then the two firms compete for the marginal consumer; in this case firm 0 faces a demand of $\frac{1}{2 \tau}\left(p_{1}-p_{0}+\frac{\tau}{n}\right)$ (while firm 1 faces a demand of $\left.\frac{1}{2 \tau}\left(p_{0}-p_{1}+\frac{\tau}{n}\right)\right) .^{8}$

The preceding paragraph focussed on the situation where all firms face positive demand. In general, this need not be the case. For example, concentrating on the demand facing firm 0 in the clockwise direction, it is possible that $p_{0}<p_{1}-\frac{\tau}{n}$ but $p_{0}>p_{2}-\frac{\tau}{n}$. So, while all consumers prefer firm 0 over firm 1 , not all prefer firm 0 over firm 2 . Then, the demand for firm 0 would be determined by the same considerations as outlined above and depends on whether firm 0 and firm 2 compete for the marginal consumer. This illustrates the procedure that determines the demand for a firm.

\footnotetext{
${ }^{7}$ At prices $p_{0}$ and $p_{1}$, the mass of consumer who lie between firm 0 and firm 1 and get positive utility from the two firms equals $\frac{\beta-p_{0}}{\tau}$ for firm 0 and $\frac{\beta-p_{1}}{\tau}$ for firm 1 . This is obtained by solving for the mass of consumers who get zero utility from, say, firm 0 ; this is the solution of $x$ in the equation $\beta-p_{0}-\tau \cdot x=0$. Consumers closer than $x$ get positive utility from firm 0 . If the firms do not compete for the marginal consumer, it must mean that $\frac{\beta-p_{0}}{\tau}+\frac{\beta-p_{1}}{\tau}<\frac{1}{n}$, implying that the relationship between the two prices is $p_{0}>2 \beta-p_{1}-\frac{\tau}{n}$.

${ }^{8} \mathrm{We}$ see from the previous footnote that if the firms compete for the marginal consumer, it must be that $p_{0} \leq 2 \beta-p_{1}-\frac{\tau}{n}$. If a consumer (located at $x$, somewhere between firm 0 and firm 1 ) is indifferent between the two firms, it must be that he receives the same utility from either of them and so, $\beta-p_{0}-\tau \cdot x=\beta-p_{1}-\tau \cdot\left(\frac{1}{n}-x\right)$. So, $x=\frac{1}{2 \tau}\left(p_{1}-p_{0}+\frac{\tau}{n}\right)$; all consumer closer than $x$ prefer firm 0 over firm 1 and hence, under our assumptions, this is the demand for firm 0 . The demand for firm 1 is derived similarly.
} 
The profit that a firm receives is determined by the price it chooses and the amount it is able to sell, where the latter (as discussed earlier) depends on the price it chooses, the price other firms choose and the quantity it produces. Since we assume that the consumer decision is based on prices alone and we ignore spillover-demand, the quantity produced by the other firms does not affect its profit. In this paper, we assume information constraints on a firm. It is cognizant of its own marginal cost and is not aware of other profit-relevant conditions such the size of the market, the consumer valuation for the product, the preferences of the consumers for different firms (or in other words, the transportation cost), the location of the other firms and the degree of differentiation of the market. The strategy-choice of each firm and the profit it receives is observable. This leads a firm to imitate the firm that receives the highest profit and this situation ensues recurrently. The next section describes the outcome of the imitative process.

\section{Results}

Our focus is on the long-run outcome that emerges from this process of imitation augmented with experimentation. However, for the purpose of comparison, we begin by presenting the symmetric pure Nash equilibrium of this model and then proceed to the results that directly pertain to the evolution of imitation behaviour.

\subsection{Nash equilibrium}

Even though firms choose price and quantity, for the purpose of the Nash equilibrium, it is sufficient to concentrate on the situation where the firms choose prices. This is because excess supply or demand cannot be a feature of a pure Nash equilibrium - after all, given the strategies of the other firms, a firm can unilaterally increase profit by correcting for excess demand or excess supply. ${ }^{9}$ The proposition that follows describes the pure Nash equilibrium (the proof is in the appendix), which is in fact a strict Nash equilibrium.

Proposition 1. (i) Suppose $\tau>n(\beta-c)$. The unique symmetric pure strategy Nash equilibrium is described by all firms choosing the monopoly price and quantity $\left(p^{m}, q^{m}\right)=\left(\frac{\beta+c}{2}, \frac{\beta-c}{\tau}\right)$.

(ii) Suppose $\tau \in\left[\frac{2}{3} n(\beta-c), n(\beta-c)\right]$. The unique symmetric pure Nash equilibrium is described by all firms choosing the price and quantity $\left(p^{n}, q^{n}\right)=\left(\beta-\frac{\tau}{2 n}, \frac{1}{n}\right)$.

\footnotetext{
${ }^{9}$ To be more precise, this would be true if the Nash equilibrium involves price(s) above marginal cost; if for example, the Nash equilibrium were characterised by all firms choosing marginal cost, then excess demand might be a feature of a Nash equilibrium as correcting for it does not lead to strictly higher profit. As we will see in the proposition to follow, the Nash equilibrium does not involve marginal-cost pricing, and so the assertion made in the text is true.
} 
(iii) Suppose $\tau<\frac{2}{3} n(\beta-c)$. The unique symmetric pure Nash equilibrium is described by all firms choosing the price and quantity $\left(p^{c}, q^{c}\right)=\left(c+\frac{\tau}{n}, \frac{1}{n}\right)$.

The proposition reveals that the Nash equilibrium price varies with the magnitude of the transportation cost $\tau$. In addition, when $\tau=n(\beta-c)$, then $p^{m}=p^{n}$ (i.e. $\frac{\beta+c}{2}=\beta-\frac{\tau}{2 n}$ ); and when $\tau=\frac{2}{3} n(\beta-c)$, then $p^{n}=p^{c}$ (i.e. $\beta-\frac{\tau}{2 n}=c+\frac{\tau}{n}$ ). This implies that the equilibrium price is a continuous function of $\tau$. Further, the equilibrium price increases with the transaction cost up to a value of $\tau=\frac{2}{3} n(\beta-c)$, then up to $\tau=n(\beta-c)$ it decreases, from whereon it does not change with respect to transportation cost. We postpone a discussion of other qualitative features of the Nash equilibrium till Subsection 3.4.

\subsection{Imitation, evolution and stochastic stability}

Firms choose price and quantity independently and simultaneously in a situation of recurrent interaction. Since a firm knows its own marginal cost, we assume that it does not price below it. The prices chosen determine the demand that each firm faces while the amount that a firm actually sells is the minimum of the quantity it chooses and the demand it faces and accordingly, it receives its profit. The price, quantity and profit of each firm is observable, and each firm imitates the actions of the firm that received the highest profit. If more than one firm receives the highest profit with disparate actions, we assume that there is a positive probability of each of these firms (which receive the highest profit) imitating the other. ${ }^{10}$ We call this the unperturbed process of imitation.

The state of the process is described by the price and quantity of each firm at each point in time; suppressing the time-index, a state is therefore denoted by $\left(p_{0}, q_{0}, \ldots, p_{n-1}, q_{n-1}\right)$. A state is said to be absorbing when there is no possibility of transiting to another state by imitation. A state where all firms choose identical prices and quantities is said to be monomorphic. The specified imitation dynamic gives rise to the following proposition.

Proposition 2. The set of absorbing states consists precisely of all monomorphic states.

Proof. A monomorphic state is clearly absorbing as firms receive equal profits and have the same actions - this leaves no further scope for imitation. On the other hand, if we are in a state where firms realize unequal profits, then firms that realise lower profit imitate the firms that receive the highest profit; if we are in a state where firms realize equal profit with disparate actions, the positive probability of imitation makes this state transient. Thus, from

\footnotetext{
${ }^{10}$ This assumption is only to simplify what follows. The set of absorbing states (to be defined soon) would be larger if we assume firms which receive the highest profit possibly with different strategies, hold on to their strategy; but it has no bearing on the stochastically stable outcome.
} 
a non-monomorphic state, the process converges to a monomorphic state in finite time. ${ }^{11}$

We now introduce the possibility of firms experimenting with their strategies. Each firm, with probability $\varepsilon$, chooses a random price-quantity pair. This is meant to represent a strategy revision rule that is not necessarily guided by imitation of the most successful firm. Without experimentation, the imitation process would converge to an absorbing state that depends on the initial state. But, experimentation makes it possible to transit from an absorbing state of the unperturbed imitation process. In fact, the experimentation-augmented imitation dynamic, also called the perturbed process, has no absorbing states. Henceforth, whenever we mention absorbing states, we refer to the absorbing states of the unperturbed process. Experimentations make it possible to transit from one absorbing state to another with experimentation. For example, if one firm experiments with a particular price-quantity choice and on doing so, receives a higher profit than all other firms, then the other firms imitate the action of the experimenting firm. However, transiting from an absorbing state may require more than one experimenting firm. The resistance of an absorbing state towards such experimentation is an indication of its stability. In fact, the set of stochastically stable states consists of the states that are most resistant to experimentation. ${ }^{12}$ The next proposition presents the stochastically stable state of the imitation dynamic (the proof of which is in the appendix).

Proposition 3. (i) Suppose $\tau>n(\beta-c)$. In the stochastically stable state, all firms choose the monopoly price and quantity $\left(p^{m}, q^{m}\right)=\left(\frac{\beta+c}{2}, \frac{\beta-c}{\tau}\right)$.

(ii) Suppose $\tau \in\left[\frac{2}{3} n(\beta-c), n(\beta-c)\right]$. In the stochastically stable state, all firms choose the price and quantity $\left(p^{n}, q^{n}\right)=\left(\beta-\frac{\tau}{2 n}, \frac{1}{n}\right)$.

(iii) Suppose $\tau<\frac{2}{3} n(\beta-c)$. In the stochastically stable state, all firms choose the price and quantity $\left(p^{c}, q^{c}\right)=\left(c+\frac{\tau}{n}, \frac{1}{n}\right)$.

The reason for stochastic stability of the states mentioned in the proposition is related to the relative ease of transiting into these states from other absorbing states using experimentations and, at the same time, the relative difficulty of transiting away from it to other absorbing states. We provide a sketch of the proof here. Let us represent the stochastically stable state as one where all firms choose the same price and quantity, $\left(p^{*}, q^{*}\right)$. Suppose that the state is described by an absorbing state different from the stochastically stable state. If a firm experiments with the price $p^{*}$ in combination with some suitably chosen quantity $q^{\prime}$ (which

\footnotetext{
${ }^{11}$ In particular, a monomorphic state where all firms receive identical negative profits is absorbing as well because imitation does not lead to a transition to another state.

${ }^{12}$ For a more detailed exposition of stochastic stability, see, for example, Young (1993) or Kandori et al. (1993).
} 
may not, in general, be the demand faced by the firm), then it is at least as profitable. The strategy of this firm $\left(p^{*}, q^{\prime}\right)$ is imitated by the other firms (with positive probability) and this brings the process to a new absorbing state where all firms choose $\left(p^{*}, q^{\prime}\right)$. Now, if some firm experiments with $q^{*}$ while keeping the price unchanged, then it receives the highest profit simply because it produces the market clearing quantity in a situation where price exceeds marginal cost. Imitation of this strategy by the other firms brings the system to the state that we claim to be stochastically stable. Hence, the transition from any other absorbing state was possible with a sequence of single-firm experimentations. On the other hand, a transition from the state(s) that we claim to be stochastically stable is not possible by singlefirm experimentations. This explains the mechanics behind stochastic stability of the states mentioned in the proposition.

One may have noticed that the stochastically stable outcome corresponds with the unique symmetric Nash equilibrium for all levels of the transportation costs. The driving forces behind this feature are discussed in more detail in the next subsection.

Figure 1 illustrates the relation between stochastically stable state prices and transportation cost. When the transportation costs are high as in subcase (i), in the stochastically stable state, firms partially serve the market and choose the monopoly price and quantity. The reason for this is that high transportation costs make it difficult for the firms to attract consumers not close enough with a price at least equal to marginal cost. This gives each firm some degree of market power, which is manifested in monopoly price and quantity in the stochastically stable state. As the transportation costs decrease to the range in subcase (ii) of the proposition, in the stochastically stable state, firms serve the entire market but the surplus of the marginal consumers is fully extracted. For lower values of the transportation cost, as in subcase (iii), firms cannot refrain from competition and the price gradually decreases as transportation costs get smaller, finally landing at marginal cost level. In this subcase, the entire market is served and marginal consumers receive a positive net utility. For transportation costs in the interval $\left(\frac{1}{2} n(\beta-c), n(\beta-c)\right)$, the price is above monopoly price. ${ }^{13}$

\subsection{Stochastic stability and Nash equilibrium: A comparison}

A comparison of Proposition 1 and Proposition 3 reveals that the stochastically stable outcome under imitation coincides with the Nash equilibrium. It is often observed that imitation leads to a "spite" equilibrium where relative profit concerns dominate and so, an action which reduces own profit while reducing the profit of the rivals by a greater extent is (in a sense)

\footnotetext{
${ }^{13}$ For (iii), $c+\frac{\tau}{n}>\frac{\beta+c}{2}$ if and only if $\tau>\frac{1}{2} n(\beta-c)$. For (ii), $\beta-\frac{\tau}{2 n}>\frac{\beta+c}{2}$ if and only if $\tau<n(\beta-c)$.
} 


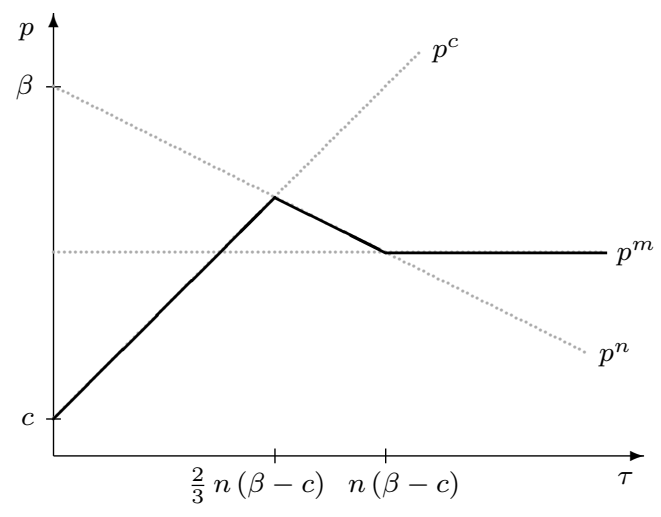

Figure 1: Stochastically stable state prices as a function of transportation costs.

more easily adopted by firms. This may result in the stochastically stable outcome under imitation leading not being a Nash equilibrium (for example, the stochastically stable state of the Cournot model in Vega-Redondo (1997) is the Walrasian equilibrium). Even though such incentives are present in our model, the stochastically stable outcome is also the Nash outcome.

The reason for this is that in this model, experimentation (in context of stochastic stability) by a firm plays a role that mirrors unilateral deviation (in context of Nash equilibrium). To elaborate, in a Nash equilibrium, firms would compare own profit to the profit on a unilateral deviation to another price-quantity pair while an experimentation by a firm would lead the system out of the current absorbing state if the price-quantity pair it experiments with gives it a higher profit compared to the other firms. Thus, while the only determinant of a Nash equilibrium is the effect on own profit of the deviating firm, the effect on own profit and on the rivals profit together determine the stability of an absorbing state against experimentations. Interestingly, when there are at least four firms, the above two are remarkably similar. We try to convey the intuition behind the equivalence between the strict Nash equilibrium strategy profile and the stochastically stable outcome, and why the outcomes that are not supported by a Nash equilibrium are not stochastically stable.

Firstly, suppose the process is in an absorbing state and so, all firms receive the same profit. Now, if a firm experiments and, on doing so, does not affect the profit of the other firms, then the experimentation can lead to a transition out of that state when it is at least as profitable (as then, the other firms will tend to imitate the strategy of the experimenting firm). But, since the experimentation does not affect the profit of the other firms, the successful experimentation is equivalent to a profitable unilateral deviation. So, if the experimentation leads to a transition from the absorbing state, it means that a deviation that is at least as profitable exists and so it cannot be a strict Nash equilibrium. In the other direction, if 
the experimentation does not lead to a transition from the absorbing state, it means that a deviation that is at least as profitable does not exist and so it is a (strict) Nash equilibrium. Since, in our model, a transition from the stochastically stable state cannot occur with a single experimentation and since a transition from the other absorbing states can happen with a single experimentation, we see the relationship between the two solution concepts.

So far, we assumed that the experimentation of a firm did not affect the profit of the rival firms. Now, suppose that it does, but that the experimenting firm cannot affect the profit of all firms, i.e. there is at least one firm whose profit is unaffected. This would happen when the lowest possible price, which is at marginal cost, is not sufficient to draw away customers from this unaffected firm that we assume to exist. This necessitates the presence of at least four firms. ${ }^{14}$ Let $\pi$ denote the profit that each firm received in the initial absorbing state prior to experimentation by a firm. The firms first in line of fire of an experimentation are the two firms that are closest to the experimenting firm and suppose that the profits of these two firms (and possibly others) are depressed by the experimentation. Then, the unaffected firm is the most successful firm (there can be multiple of them) amongst the non-experimenting firms. The experimentation is successful if the experimenting firm earns a profit (say, $\pi^{\prime}$ ) that is at least as profitable as this unaffected firm (that receives $\pi$ ). This being possible implies that the initial situation is not a strict Nash equilibrium - after all, a firm could have unilaterally deviated with the same price-quantity pair and received a higher profit $\left(\pi^{\prime} \geq \pi\right)$. Vice versa, when transition from an absorbing state is not affected by a single-firm experimentation (and so needs experimentation by more than one firm), it signifies that a unilateral deviation does not even lead to at least as much profit; so, it is a (strict) Nash equilibrium. Since, in our model, the stochastically stable state cannot be upset by a single experimentation, it is also a Nash equilibrium. Furthermore, since all absorbing states that are not stochastically stable can be upset by a single experimentation, they are not strict Nash equilibria.

Finally, let us consider the situation where an experimentation by a firm affects the profit of all other firms. This is the situation where spite has the maximum potential to act, say, by reducing the profit of all the rival firms more than the own profit is depressed. However, it can be seen (in the proof of subcase (iii) of Proposition 3), that if firms are in the stochastically stable state, and a firm experiments, then (a) it always decreases its own profit and (b) it is never able to decrease its rivals' profits more than it decreases its own profit. Thus, experimentation by a firm does not leave it better off absolutely or relatively. On the other hand, from a state that is not stochastically stable, there is an experimentation that increases

\footnotetext{
${ }^{14}$ Because of the symmetry of position of the firms, if a firm affects the neighbouring firm on the left, it also affects the neighbouring firm on the right to the same extent. This implies there have to be at least four firms for the existence of a firm unaffected by the experimentation.
} 
the profit of the firm, which at the same time, gives it a profit at least as high as the other firms. Thus, a successful experimentation is also an equally profitable unilateral deviation. This explains the coincidence of (strict) Nash equilibrium and stochastic stability under imitation.

\subsection{Qualitative features of the (long-run) equilibrium}

The equilibrium price is a continuous function of transportation costs $\tau$. It increases with this cost up to a value of $\tau=\frac{2}{3} n(\beta-c)$ to a price level above monopoly prices, from there it decreases to reach the monopoly price at $\tau=n(\beta-c)$, and settles there for higher values of the transportation costs (recall Figure 1).

When transportation costs are high as in subcase (i), the firms charge the price that they would charge if they were a monopolist (on the Salop circle). The market is not fully served in the sense that there is a positive mass of consumers who prefer not to acquire the good. This implies, in turn, that firms do not compete for the marginal consumer and this is driven by the fact that the transportation costs are too high. If firms were to try to serve the entire market, then the price would have to be reduced substantially (possibly even below marginal cost level) and the increase in the market size would not justify (in terms of relative or absolute profit) this reduction in price.

When transportation costs decrease to the range in subcase (ii), the firms choose a price such that the entire market is served (i.e. all consumers acquire the product) and they price non-aggressively. In fact, they share the market while extracting all surplus from the marginal consumers, i.e. the consumers located exactly in between two firms (at a distance of $\frac{1}{2 n}$ from either firm) receive net utility equal to 0 . While this may seem similar to a collusive outcome, it is clearly not so. A unilateral price decrease, along with the optimal quantity adjustment, by one firm in order to attract more consumers is actually (absolutely and relatively) profitreducing; so a decrease in price (which would lead to 'real' competition amongst firms) neither leads to a higher absolute profit as in the Nash-equilibrium paradigm nor to a (weakly) higher profit relative to the other firms as in the context of the imitation paradigm. Within this range of transportation costs, the price is actually decreasing with the transportation costs implying that more market differentiation may lead to lower prices. This striking phenomenon is caused by the firms extracting all excess surplus from the marginal consumers (whose utility is decreasing in the transportation cost) in a fully served market.

As transportation costs decreases beyond the threshold dividing subcases (ii) and (iii), the equilibrium price is given by a mark-up over marginal cost. The market is fully-served and all consumers enjoy a positive net surplus. As the market becomes homogeneous (i.e. $\tau$ approaches zero), the price approaches the competitive price. This parallels the result in 
Vega-Redondo (1997), where the evolutionary Cournot-model with imitating firms leads to the competitive outcome in homogeneous markets.

The effect of an increase in the number of firms $(n)$ on the equilibrium price is depicted it Figure 2. In this figure, the solid (dotted) line depicts prices as a function of the transportation costs for smaller (larger) number of firms. For high levels of the transportation costs, the firms charge the price that they would charge if they were a monopolist and, hence, the price does not depend on the number of firms. Interestingly, for middle ranged values of the transportation costs, the dotted line is above the solid line, meaning that, ceteris paribus, prices increase with the number of firms. This is a reflection of the fact that for this range the market is divided among firms and maximal surplus is extracted from consumers. As the number of firms increase, the marginal consumers (i.e. the consumers located exactly in between two firms) are closer to the firms on either side, and in order to fully extract these consumers' surplus, the price has to be higher. Thus, more competition may actually lead to higher prices. ${ }^{15}$ For low levels of the transportation costs, we recover the standard intuition that more competition leads to a lower price. The range of transportation costs for which this subcase is valid is increasing in the number of firms. In fact, when the number of firms grows large, prices converge pointwise to marginal cost (for all levels of transportation costs).

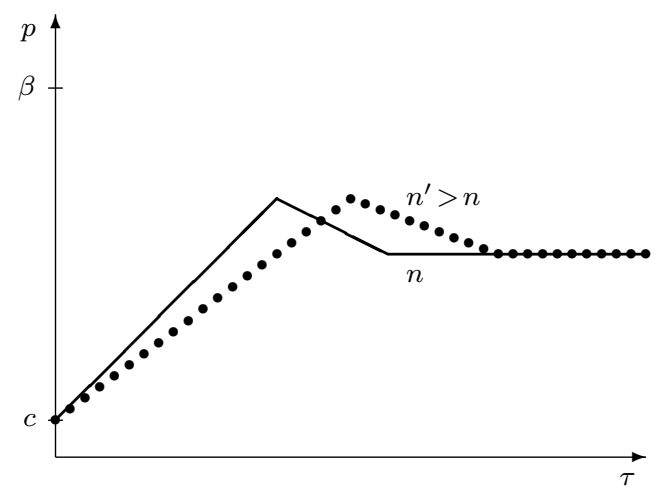

Figure 2: Relation between number of firms and stochastically stable state prices.

The effect of a decrease in consumer valuation $(\beta)$ on the equilibrium price depends on the transportation costs, as is illustrated in Figure 3. In this figure, the solid (dotted) line depicts prices as a function of the transportation costs for larger (smaller) consumer valuation. For high levels of transportation cost such that firms effectively operate as monopolists, a lower

\footnotetext{
${ }^{15}$ To the best of our belief, this point has not been made in the literature, especially in context of the Nash equilibrium, probably due to the focus on the parameter range given by the third subcase (low level of differentiation) in the proposition, leading to the conclusion that competition on the Salop circle leads to lower prices.
} 
consumer valuation clearly yields lower prices. This is also the case for transportation costs where firms are mutually non-aggressive and extract maximal surplus from the consumers, simply because there is less to extract. Only for transportation costs low enough to generate 'real' competition, and prices equal a mark-up above marginal cost, prices are invariant to changes in consumer valuation. As we see in Proposition 1 or 3 , there is a critical value of transportation cost at $\tau=n(\beta-c)$ above which the market is partially served. A decrease in consumer valuation decreases this critical value and shrinks the range for which full coverage is obtained. With respect to market coverage, a decrease in consumer valuation leads to a decrease in the critical transportation costs above which the market is no longer fully covered.

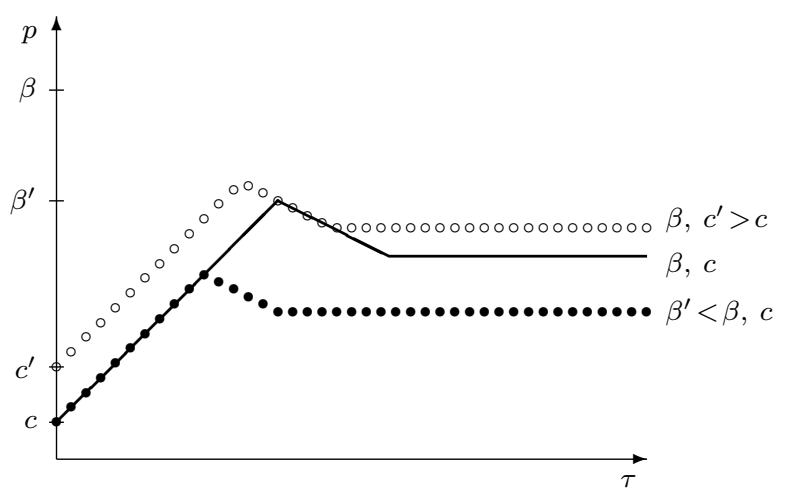

Figure 3: Relation between consumer valuation (marginal costs) and stochastically stable state prices.

The effect with respect to marginal cost $(c)$ is that prices are nondecreasing in marginal cost (compare solid line and circled line in the figure); the only part where it is not increasing is at medium values of transportation cost (subcase (ii), where prices are independent of marginal costs because prices are such that maximal surplus is extracted, and consumers' surplus is independent of marginal cost). An increase in this parameter has the effect to decrease the critical level of the transportation costs above which the market is no longer fully covered.

\section{Discussion}

The model studied in this paper assumes firms to choose price and quantity. Doing so, the model captures situations where firms may have independence to choose prices - a very reasonable assumption especially in differentiated markets - while production is not on demand but in advance. Yet, we see that the stochastically stable state of the imitation protocol leads to market-clearing outcomes. It would be erroneous to conclude that a model assuming imi- 
tation on prices only and production on demand (thereby imposing market clearing) always leads to similar outcomes. The reason for this equivalence is that the stochastically stable state prices are above marginal cost. If this were not the case (i.e. if the (set of) stochastically stable states were to include pricing at marginal cost), the imitation model with prices and quantities would not be equivalent to an imitation model with prices only (where market clearing is imposed). The reason is that once states with marginal cost pricing are stochastically stable, then a firm that produces less than the demand it faces obtains the same profit as a firm that chooses a quantity equal to the demand. This easily opens up the possibility of other firms imitating the firm that produces less than the demand it faces, leading to a situation where the market does not clear. So, the transition from the market-clearing state where firms price at marginal cost to a non-market-clearing state where firms price at marginal cost can be realised after a single experimentation. As a result, if the former state is in the set of stochastically stable states, so is the latter. Such a possibility is precluded by an imitation model where firms only choose prices and produce on demand. ${ }^{16}$

Throughout the paper, we assumed that there are at least four firms and in Subsection 3.3 we indicated the importance of this assumption. If instead, there were two or three firms in the market, the spite effect would dominate and may lead to stochastically stable states that are not necessarily Nash equilibrium outcomes. The reason for this is simply that if a firm now experiments such that the profits of its rivals are reduced more than its own profit, then the rival firms imitate the experimenting firm. The stabilising effect of a firm that is unaffected (a condition that requires presence of at least four firms) is no longer present. In fact, Khan and Peeters (2011) present a similar model of price and quantity setting by imitating firms in a differentiated market, with the difference being that it involves a duopoly with the two competitors situated at the two ends of a Hotelling line. In this case, the stochastically stable set consists of states that are not Nash equilibria.

For a firm to be able to imitate the most successful firm, it is necessary that the actions and profits of all other firms are observable. However, one could think of situations where observability is incomplete, and firms that are not being able to observe all other firms imitate the most profitable firm they observe. What bearing would such an incomplete observability have on the stochastically stable outcome? Our results are fairly robust to this concern. Ultimately, complete observability is somewhat of a luxury; a minimum amount of observability of three other firms supports the results that we have presented. ${ }^{17}$ The

\footnotetext{
${ }^{16}$ This observation is the driving force behind the stochastic stability of non-market-clearing states in Khan and Peeters (2011). Although that paper uses a slightly different experimentation structure, the results here are robust to reasonable variations in experimentation structure.

${ }^{17}$ This implies that it is possible to construct a network on the Salop circle where the links of the network
} 
reason for this is similar to the argument made in the previous paragraph. If a firm observes less than three firms, it leaves open the possibility that a firm observes only its immediate neighbours (i.e. one neighbour on each side). Then, for all practical purposes, it is equivalent to a situation where there are only three firms - after all, from the perspective of a firm that has little information apart from its own marginal cost, there is hardly a difference between a market with three firms and a situation where there are more than three firms but the firm is aware of only two of them, which are symmetrically situated. We have already argued for the importance of at least four firms in supporting the results obtained, and in a sense, it is also the reason behind the minimum observability condition.

\section{Conclusion}

We present an evolutionary model of firm behaviour in a horizontally differentiated market. Firms are equidistantly located on the circumference of a unit circle, while consumers are distributed uniformly along it. A firms chooses price and quantity, while consumers make their decision to purchase based on the announced prices. We assume a very limited informational environment: a firm needs to know only its own marginal cost. At the end of each period, the strategy and profit of each firm is observable and a firm imitates the strategy of the most successful firm, while occasionally experimenting with random strategies.

The stochastically stable outcome of this process depends on the level of differentiation and coincides with the Nash equilibrium of the underlying game, in spite of the simple heuristics used by a firm. When the level of differentiation is high, in the stochastically stable outcome, firms choose monopoly prices and outputs. At moderate levels of differentiation, firms price such that the surplus of the marginal consumers is fully extracted; nevertheless, the entire market is served. At low level of differentiation, firms price at a mark-up over marginal cost and the entire market is served. In all cases, market clearing arises endogenously. Interestingly, for some range of differentiation levels, an increase in the number of firms may lead to higher prices and an increased level of differentiation may lead to lower prices.

\section{Appendix}

\section{Proof of Proposition 1}

Statement (i): $\tau>n(\beta-c)$. First, in (a), we show that each firm choosing the strategy

indicate observability. If the network is connected (i.e. all nodes should be reachable from every node) and all firms have at least three links, then imitation of the most successful firm that is observed leads to identical results. 
$\left(p^{m}, q^{m}\right)=\left(\frac{\beta+c}{2}, \frac{\beta-c}{\tau}\right)$ is a strict Nash equilibrium, by showing that all unilateral deviations are profit-reducing. Next, in (b), we show that there does not exist any other symmetric pure Nash equilibrium.

Part (a) Suppose each firm chooses the monopoly price and quantity pair $\left(p^{m}, q^{m}\right)=$ $\left(\frac{\beta+c}{2}, \frac{\beta-c}{\tau}\right)$. Then, firms do not compete for the marginal consumer. Firms would compete for the marginal consumer (while setting the same price) if the prices were below $\beta-\frac{\tau}{2 n}$. However, the restriction $\tau \geq n(\beta-c)$ ensures that $p^{m}=\frac{\beta+c}{2} \geq \beta-\frac{\tau}{2 n}$. So, each firm receives the monopoly profit of $\left(p^{m}-c\right) q^{m}=\frac{(\beta-c)^{2}}{2 \tau}$.

An important price level when considering a unilateral deviation is at $\hat{p}=2 \beta-p^{m}-\frac{\tau}{n}$. Prices below this level induce competition for the marginal consumer with the neighbouring firm. As it is clear that a unilateral deviation can never increase the profit for a firm deviating to a price above this level, consider a deviation to a price $p^{\prime}$ below $\hat{p}$. This deviation induces competition for the marginal consumer with the neighbouring firms and the demand that it faces equals $\frac{p^{m}-p^{\prime}+\frac{\tau}{n}}{\tau}$. The deviation would be at least as profitable for the firm if

$$
\left(p^{\prime}-c\right) \frac{p^{m}-p^{\prime}+\frac{\tau}{n}}{\tau} \geq \frac{(\beta-c)^{2}}{2 \tau} .
$$

The left hand-side of the expression (i.e. the profit after deviation) is maximised at $p^{*}=$ $\frac{1}{2} \cdot\left(p^{m}+c+\frac{\tau}{n}\right)$. However, $\tau \geq n(\beta-c)$ implies $p^{*}>\hat{p}$, and so the price $p^{*}$ cannot induce competition for the marginal consumer. So, we have to consider the deviating price that maximises the profit on the left-hand side while satisfying this assumption. From the shape of the profit function of the firm on deviation to price $p^{\prime}$, it follows that the constrained profit-maximising price is given by $p^{\circ}=2 \beta-p^{m}-\frac{\tau}{n}$. It can be easily verified that for $p^{\prime}=p^{\circ}$ the inequality above cannot be satisfied. Hence, even the best possible deviation decreases a firm's profit, leading to the conclusion that the state where all firms choose $\left(p^{m}, q^{m}\right)$ is a strict Nash equilibrium.

Part (b) Suppose that we are in a state where all firms choose the same price and quantity $(p, q)$. First, consider the case $p>2 \beta-p^{m}-\frac{\tau}{n}$ with $p \neq p^{m}$. In this case, if a firm deviates to $\left(p^{m}, q^{m}\right)$, then it does not compete for the marginal consumer with its neighbours and hence earns monopoly profit, which must be higher than the pre-deviation profit. Hence, states where all firms choose the same price and quantity $(p, q)$, with $p>2 \beta-p^{m}-\frac{\tau}{n}$ and $p \neq p^{m}$, cannot be Nash equilibria.

Now, consider the case $p \leq 2 \beta-p^{m}-\frac{\tau}{n}$. From the assumption $\tau \geq n(\beta-c)$, it follows that $p \leq 2 \beta-p^{m}-\frac{\tau}{n} \leq \beta-\frac{\tau}{2 n}$. Consequently, at prices $p$, firms compete for the marginal consumer and the demand that they face equals $\frac{1}{n}$. So, in this state, each firm enjoys a profit of $\frac{p-c}{n}$. Now, suppose a firm deviates to the monopoly price $p^{m}$. As this deviating firm still competes for the marginal consumer, the demand it faces equals $\frac{p-p^{m}+\frac{\tau}{n}}{\tau}$; let the firm also 
choose this quantity. The profit from the deviation is higher than the profit before deviation if

$$
\left(p^{m}-c\right) \frac{p-p^{m}+\frac{\tau}{n}}{\tau}-(p-c) \frac{1}{n}>0 .
$$

The partial derivative of the left hand-side expression with respect to $p$ is negative, meaning that it is minimised at the highest value of $p$ subject to the constraint $p \leq 2 \beta-p^{m}-\frac{\tau}{n}$, which is at the price where this constraint is binding. Now, if the inequality is already satisfied for $p=2 \beta-p^{m}-\frac{\tau}{n}$, it is satisfied for all lower values of $p$. For $p=2 \beta-p^{m}-\frac{\tau}{n}$, the inequality can be rewritten as $\frac{(\beta-c)^{2}}{2 \tau}>(p-c) \frac{1}{n}$. As the left hand-side equals monopoly profit - which is the maximum a firm could ever get - and the right hand-side represents a feasible profit, this inequality is always satisfied. We can conclude that also states where all firms choose the same price and quantity $(p, q)$, with $p \leq 2 \beta-p^{m}-\frac{\tau}{n}$, cannot be Nash equilibria.

Statement (ii): $\tau \in\left[\frac{2}{3} n(\beta-c), n(\beta-c)\right]$. First, in (a), we show that each firm choosing $\left(p^{n}, q^{n}\right)=\left(\beta-\frac{\tau}{2 n}, \frac{1}{n}\right)$ is a strict Nash equilibrium. Then, in (b), we show that there does not exist any other symmetric pure Nash equilibrium.

Part (a) Suppose that each firm chooses $\left(p^{n}, q^{n}\right)$. The profit that each of them receive equals $\frac{1}{n}\left(p^{n}-c\right)$. If a firm deviates with a different price-quantity pair $\left(p^{\prime}, q^{\prime}\right)$ with $p^{\prime}>p^{n}$, then the deviating firm does not compete with its neighbouring firms. As a result, the demand the firm faces equals $\frac{\beta-p}{\tau}$ and the profit equals $\left(p^{\prime}-c\right) \frac{\beta-p^{\prime}}{\tau}$ and is decreasing in $p^{\prime}$ for $p^{\prime} \geq \frac{\beta+c}{2}$. From $\tau<n(\beta-c)$, it follows that $p^{n}=\beta-\frac{\tau}{2 n}>\frac{\beta+c}{2}$. So, a deviation to a price $p^{\prime}$ higher than $p^{n}$ implies $p^{\prime} \geq \frac{\beta+c}{2}$, and so, the firm receives a strictly lower profit. Thus, there does not exists a profitable deviation for a firm when it chooses a higher price.

So now, let a firm deviate with a different price-quantity pair $\left(p^{\prime}, q^{\prime}\right)$ with $p^{\prime}<p^{n}$. The deviating firm now steals away some consumers of the two neighbouring firms and faces a demand of $\frac{p-p^{\prime}+\frac{\tau}{n}}{\tau}$; let this also be the quantity the firm chooses. This will represent a profitable deviation only if

$$
\left(p^{\prime}-c\right) \frac{p^{n}-p^{\prime}+\frac{\tau}{n}}{\tau}-\left(p^{n}-c\right) \frac{1}{n} \geq 0 .
$$

The left hand-side expression is maximised for $p^{*}=\frac{1}{2}\left(p^{n}+c+\frac{\tau}{2 n}\right)$. However, from $\tau>$ $\frac{2}{3} n(\beta-c)$ it follows that $p^{*}>p^{n}$. Hence, subject to the constraint $p^{\prime} \leq p^{n}$, the expression is maximised at $p^{\circ}=p^{n}$. This choice does, however, not represent a deviation. Any other true deviation implies a negative gain. So, there is no deviation that improves the profit.

Part (b) Suppose we are in the state where all firms choose the same price-quantity pair $(p, q)$ with $p>p^{n}$. Then, the firms are not competing for the marginal consumer and the demand that each firm faces is equal to $2 \frac{\beta-p}{\tau}$, and each firm enjoys a profit of $2(p-c) \frac{\beta-p}{\tau}$. 
This profit is decreasing in $p$ if $p>\frac{\beta+c}{2}\left(=p^{m}\right)$. Since $p^{m}<p^{n}<p$, a firm deviating to $\left(p^{n}, q^{n}\right)$ will increase its profit. Hence, states where firms choose an identical price-quantity pair $(p, q)$, with $p>p^{n}$, are not Nash equilibria.

Suppose instead that all firms choose the price-quantity pair $(p, q)$ with $p<p^{n}$. Now, firms compete for the marginal consumer. Since all firms choose the same price, each firm faces a demand of $\frac{1}{n}$ and receives a profit of $\frac{1}{n}(p-c)$. Consider a firm deviating to $\left(p^{n}, q^{\prime}\right)$. As this firm chooses a higher price than its neighbouring firms, it loses some of its consumers and will be left with $\frac{p-p^{n}+\frac{\tau}{n}}{\tau}$ consumers. ${ }^{18}$ Suppose that the deviating firm adapts the quantity optimally given the price: $q^{\prime}=\frac{p-p^{n}+\frac{\tau}{n}}{\tau}$. Now, this would be a profitable deviation if

$$
\left(p^{n}-c\right) \frac{p-p^{n}+\frac{\tau}{n}}{\tau}-(p-c) \frac{1}{n}>0 .
$$

The derivative of the left hand-side expression with respect to $p$ is $\frac{1}{\tau}\left[p^{n}-\left(c+\frac{\tau}{n}\right)\right]$, which is negative as $\tau>\frac{2}{3} n(\beta-c)$. So, under the constraint $p<p^{n}$, the expression is minimised at $p=p^{n}$. At $p=p^{n}$, it is exactly equal to 0 . Therefore, it is positive for all other prices $p<p^{n}$. Thus, the deviation considered is a profitable deviation in a state where firms choose an identical price-quantity pair $(p, q)$ with $p<p^{n}$, and such states are not Nash equilibria.

Statement (iii): $\tau<\frac{2}{3} n(\beta-c)$. For this part of the proposition, see, for example, Tirole (1988).

\section{Proof of Proposition 3}

Statement (i): $\tau>n(\beta-c)$. First, in (a), we show that it takes a series of single-firm experimentations to get to the state $\left(p^{m}, q^{m}\right)=\left(\frac{\beta+c}{2}, \frac{\beta-c}{\tau}\right)$. Next, in (b), we show that it requires more than a single-firm experimentation to transit out of it.

Part (a) Suppose we are in an absorbing state where each firm sets the price at $p$ and produces a quantity $q$. If in this state the market does not clear, then a single experimentation by a firm to the quantity choice equal to the demand it faces (without a change in price), gives the firm at least as much profit. In fact, the experimenting firm obtains a higher profit compared to its competitors (if $p$ is not equal to marginal cost - in which case a market-clearing state also requires just one experimentation). So, we can restrict attention to absorbing states that are market-clearing, and so the quantity that firms produce equals the demand that they face. We have already demonstrated in part (b) of the proof of Proposition 1(i) that from any (market-clearing) absorbing state other than $\left(p^{m}, q^{m}\right)$, if a firm chooses to deviate to a price

\footnotetext{
${ }^{18}$ The deviating firm always faces a strictly positive demand. There would be no demand if and only if $p^{n}=\beta+\frac{\tau}{2 n}>p+\frac{\tau}{n}$, as then all consumers would receive higher utility by acquiring from its neighbouring firm. This condition is satisfied if and only if $\tau<\frac{2}{3} n(\beta-p)$ and this is not satisfied for the lowest possible price of $p$, which is $p=c$. Hence, the deviating firm faces a positive demand even when other firms price at marginal cost and, so, it faces positive demand when the other firms choose any price $p<p^{n}$.
} 
of $p^{m}$ in combination with some quantity, then it receives a higher profit, and so it represents a profitable deviation. But now, we make the point that this deviation, or experimentation (in this context), also gives the firm a highest profit amongst all firms.

First, when the price in the initial state, $p$, is such that $p<2 \beta-p^{m}-\frac{\tau}{n}$, then the experimentation by a firm to $p^{m}$ does not affect the profit of the other firms. This is because the experimenting firm chooses a higher price than the other firms (this follows from $\tau>$ $n(\beta-c))$ and so, does not attract consumers away from any of the other firms. However, some consumers of the experimenting firm might be tempted to purchase from the neighbouring firms. However, these neighbouring firms are not able to cater to this additional demand as they are constrained to the quantity that was previously market-clearing. Hence, the other firms maintain the old level of profit (i.e. their profit is not affected by the experimentation), which is equal to the profit of the experimenting firm prior to the experimentation. If, as we have shown, the experimenting firm improves on its own profit, it follows that after the experimentation, it also gets a higher profit relative to the other firms.

Second, when the price in the initial state, $p$, is such that $p \geq 2 \beta-p^{m}-\frac{\tau}{n}$, then the experimentation by a firm to $p^{m}$ again does not affect the profit of the other firms. This is because experimentation by a firm to $p^{m}$ in combination with some quantity results in the experimenting firm obtaining a locally segregated market; i.e. it does not compete with its neighbours for the marginal consumer. As a result, it does not attract consumers from the other firms; neither are the other firms able to cater to any additional consumers due to them producing the quantity that was market-clearing. Consequently, by the reason advanced in the paragraph above, the experimenting firm receives the highest profit amongst all firms.

So, in either of the two cases, all firms imitate the experimenting firm, resulting in an absorbing state where all of them price at $p^{m}$ and produce some identical quantity. ${ }^{19}$ Now, after all firms have imitated the experimenting firm, suppose some firm experiments with the quantity $q^{m}$, which is the actual demand that each individual firm faces, given the prevailing price. The firm obtains the highest profit because it produces the demand that it faces and the price is higher than marginal cost. So, it is imitated by all the other firms, and this brings the process to the absorbing state where each firm chooses the pair $\left(p^{m}, q^{m}\right)$; this happens with a series of single firm experimentations.

Part (b) Suppose we are in an absorbing state where each firms sets the price at $p^{m}$ and produces a quantity $q^{m}$. We have demonstrated in part (a) of the proof of Proposition 1(i) that if a firm deviates, or experiments (in this context), with any price and quantity, then it

\footnotetext{
${ }^{19}$ We show in the proof of Proposition 1(i) that the firm on deviating to $p^{m}$ in combination with the marketclearing quantity, receives a higher profit than all other firms. This implies that the firm has some freedom in 'choosing' the quantity; it does not strictly require to be the market-clearing quantity.
} 
constitutes a profit-reducing deviation for that firm. First note that even if a firm experiments with marginal cost, it cannot attract any consumers away from a firm that is not an immediate neighbour. To see this, note that $\tau>n(\beta-c)$ implies $\beta-c-\frac{\tau}{n}<0$. This means that the consumers that are farthest away from a firm experimenting to marginal cost and get nonnegative utility from consuming from this firm are situated precisely on the locations of the directly neighbouring firms. As a result, the profit of the non-neighbouring firms - the existence of which is guaranteed by the assumption of at least four firms - is not affected by the experimentation and equals the profit of the experimenting firm prior to experimentation. Hence, the experimenting firm obtains a lower profit than some other firm, and imitates back to the strategy combination of $\left(p^{m}, q^{m}\right)$.

Statement (ii): $\tau \in\left[\frac{2}{3} n(\beta-c), n(\beta-c)\right]$. First, in (a), we show that it takes a series of single-firm experimentations to get to the state $\left(p^{n}, q^{n}\right)=\left(\beta-\frac{\tau}{2 n}, \frac{1}{n}\right)$. Next, in (b), we show that it requires more than a single-firm experimentation to transit out of it.

Part (a) Suppose we are in an absorbing state where each firm sets the price at $p$ and produces a quantity $q$. As we have already established (see Subcase (i)) that it takes one singlefirm experimentation to reach a market-clearing absorbing state from a non-market clearing state, we concentrate on the former. By the arguments of part (b) of Proposition 1(ii), if a firm experiments with a price of $p^{n}$ in combination with some quantity, the firm increases its profit relative to its profit prior to the experimentation. As we will see, this implies that this experimenting firm receives a higher profit than all other firms.

First, when the price in the initial absorbing state, $p$, is such that $p<p^{n}=\beta-\frac{\tau}{2 n}$, the firms compete for the marginal consumer, and so, face identical demand of $\frac{1}{n}$ mass of consumers. As we can restrict attention to market-clearing absorbing states, the firms produce precisely this quantity. Now, when a firm experiments with the higher price $p^{n}$, in combination with some quantity, it does not draw away consumers from other firms. Some of its consumers might be tempted to purchase from one of the other firms, but the other firms cannot serve them owing to the quantity produced. Thus, the experimentation does not affect the profit earned by the other firms. So, if the experimentation considered leads to an improvement for the firm, the profit earned after experimentation must be larger than that of the other firms.

Second, when the price in the initial absorbing state, $p$, is such that $p>p^{n}=\beta-\frac{\tau}{2 n}$, the firms do not compete for the marginal consumer. They have segregated markets and each faces a demand of $\frac{\beta-p}{\tau}$. When one firm experiments with $p^{n}$, then this firm will not induce competition with its immediate neighbours. This is because (1) no consumer who is closer to the neighbouring firm would receive positive utility from purchasing from the experimenting firm, and (2) given $p>p^{n}$, the other firms attract a smaller mass of consumers. So, the 
markets are also segregated after the experimentation. Consequently, the profit of the other firms do not change before and after the experimentation. So, if the experimenting firm receives more profit after the experimentation than before the experimentation, it must imply that it gets a higher profit than all other firms.

So, all firms imitate the experimenting firm, resulting in an absorbing state where all of them price at $p^{n}$ and produce some identical quantity. ${ }^{20}$ Now, after all firms have imitated the experimenting firm, suppose some firm experiments with the quantity $q^{n}$, which is the actual demand that each individual firm faces, given the prevailing price. The firm obtains the highest profit because it produces the demand that it faces and the price is higher than marginal cost. So, it is imitated by all the other firms, and this brings the process to the absorbing state where each firm chooses the pair $\left(p^{n}, q^{n}\right)$. This happens with a series of single firm experimentations.

Part (b) Suppose we are in an absorbing state where each firms sets the price at $p^{n}$ and produces a quantity $q^{n}$. From $\tau \geq \frac{2}{3} n(\beta-c)$ it follows that an experimenting (or deviating) firm cannot attract any consumers from the firms that are not its immediate neighbours the existence of which is assured by the assumption of at least four firms - even not when experimenting to the lowest possible price at marginal cost. So, the demands of the nonneighbouring firms, and hence also their profits, are not affected due to the experimentation. As any experimentation constitutes a reduction in the profit of the firm experimenting (this is demonstrated in part (a) of the proof of Proposition 1(ii)), the experimenting firm obtains a lower profit than the non-neighbouring firms. As a consequence, the experimenting firm imitates the non-neighbouring firms due to which the system returns to the state in which all firms choose the pair $\left(p^{n}, q^{n}\right)$. We conclude that more than a single-firm experimentation is needed to get out of this state.

Statement (iii): $\tau<\frac{2}{3} n(\beta-c)$. First, in (a), we show that it takes a series of single-firm experimentations to get to the state $\left(p^{c}, q^{c}\right)=\left(c+\frac{\tau}{n}, \frac{1}{n}\right)$. Next, in (b), we show that it requires more than a single-firm experimentation to transit out of it.

Part (a) Suppose we are in an absorbing state where each firms sets the price at $p$ and produces a quantity $q$. By the argument made earlier, we can restrict attention to marketclearing states.

First, suppose that $p \leq \beta-\frac{\tau}{2 n}$, so that firms compete for the marginal consumer. As all firms choose the same price, the demand they face equals $\frac{1}{n}$, and due to our focus on marketclearing states, this is also the quantity that they produce. Now, let a firm experiment

\footnotetext{
${ }^{20}$ We show in the proof of Proposition 1(ii) that the firm on deviating to $p^{n}$ in combination with the marketclearing quantity, receives strictly higher profit than all other firms. This implies that the firm has some freedom in 'choosing' the quantity; it does not strictly require to be the market-clearing quantity.
} 
with the price $p^{c}$. As both $p^{c}$ and $p$ are lower than $\beta-\frac{\tau}{2 n}$ (the first one follows from $\tau \leq \frac{2}{3} n(\beta-c)$; the second one is by assumption), the experimenting firm competes for the marginal consumer. We assume that it adapts the production quantity perfectly to the demand. The amount of consumers the experimenting firm may capture from the other firms depends on the price difference between $p$ and $p^{c}$. We consider three cases: (1) the experimenting firm captures consumers from all rival firms except the one(s) farthest away; (2) the experimenting firm captures consumers from all rival firms, but does not capture the full market; (3) the experimenting firm captures the full market.

Case (1). The relative profit of the experimenting firm compared to the most profitable non-experimenting firm is

$$
\left(p^{c}-c\right)\left[\frac{k}{n}+\frac{p-p^{c}+\frac{\tau}{n}}{\tau}\right]-(p-c) \frac{1}{n},
$$

where the even number $k \in\{0, \ldots, n-2\}$ refers to the number of firms it captures all consumers from. For example, if $p-p^{c}<\frac{\tau}{n}$, then it does not capture all the consumers of the neighbouring firms and so $k=0$; and, if $p-p^{c} \in\left(\frac{\tau}{n}, \frac{2 \tau}{n}\right)$, then it captures all the consumers of the two neighbouring firms but not of the firms beyond that and so $k=2$. Higher values of $k$ are similarly explained. The firms whose consumers are captured by the experimenting firm are left with excess supply (in fact, the firms who have lost all their consumers incur a negative profit as they produce a positive amount but are not able to sell to any consumer.) Clearly, the most profitable firm amongst the non-experimenting firms is one of whom no consumers have been drawn away and it receives a profit of $(p-c) \frac{1}{n}$. In this case, the firm(s) farthest away from the experimenting firm is one of them. After substituting $p^{c}=c+\frac{\tau}{n}$, the expression for the relative profit simplifies to $\frac{k}{n} \frac{1}{n}$. So, for $k=0$ it is exactly equal to 0 ; for higher values of $k$ it is strictly positive. Hence, the profit of the experimenting firm is always at least as much of that of the other firms.

Case (2). The relative profit of the experimenting firm compared to the most profitable non-experimenting firm is

$$
\left(p^{c}-c\right)\left[\frac{n-2}{n}+\frac{p-p^{c}+\frac{\tau}{n}}{\tau}\right]-\left\{p \frac{p^{c}-p+\frac{\tau}{n}}{\tau}-c \frac{1}{n}\right\}
$$

if $n$ is even. This relative profit is larger than

$$
\left(p^{c}-c\right)\left[\frac{n-2}{n}+\frac{p-p^{c}+\frac{\tau}{n}}{\tau}\right]-(p-c) \frac{p^{c}-p+\frac{\tau}{n}}{\tau} .
$$

Note that, of the non-experimenting firms, only the firm farthest away receives a positive demand (equal to $\frac{p^{c}-p+\frac{\tau}{n}}{\tau}$ ) and hence receives the highest profit (possibly negative as it produces $\frac{1}{n}$ ) among the non-experimenting firms. After substituting $p^{c}=c+\frac{\tau}{n}$, the latter 
expression simplifies to

$$
\frac{n-2}{n} \frac{\tau}{n}+\frac{1}{\tau}(p-c)\left(p-c-\frac{\tau}{n}\right) .
$$

As in this case it must be that $p>c+\frac{\tau}{n}$ (otherwise the experimenting firm would not even be able to attract all the consumers of the neighbouring firms by choosing the lowest possible price of marginal cost) and $n \geq 4$, the expression and hence the relative profit is strictly positive. In case $n$ is odd, the relative profit is given by

$$
\left(p^{c}-c\right)\left[\frac{n-3}{n}+\frac{p-p^{c}+\frac{\tau}{n}}{\tau}\right]-\left\{p\left[\frac{1}{2 n}+\frac{p^{c}-p+\frac{\tau}{n}}{2 \tau}\right]-c \frac{1}{n}\right\} .
$$

This expression is larger than

$$
\left(p^{c}-c\right)\left[\frac{n-3}{n}+\frac{p-p^{c}+\frac{\tau}{n}}{\tau}\right]-(p-c)\left[\frac{1}{2 n}+\frac{p^{c}-p+\frac{\tau}{n}}{2 \tau}\right],
$$

which simplifies to

$$
\frac{n-3}{n} \frac{\tau}{n}+\frac{1}{2 \tau}(p-c)\left(p-c-\frac{\tau}{n}\right)
$$

after substituting $p^{c}=c+\frac{\tau}{n}$. Again, the final expression and hence the relative profit is positive as $p>c+\frac{\tau}{n}$ and $n \geq 4$.

Case (3). This occurs when the difference $p$ and $p^{c}$ is such that all consumers prefer to buy from the experimenting firm. This happens when $p-p^{c}>\frac{\tau}{2}$ if $n$ is even and when $p-p^{c}>\frac{(n-1) \tau}{2 n}$ if $n$ is odd. The relative profit of the experimenting firm compared to the most profitable non-experimenting firm is

$$
\left(p^{c}-c\right)-(-c) \frac{1}{n}=\frac{c+\tau}{n}
$$

Note that all other firms receive (negative) profit of $-c \frac{1}{n}$ as they incur the cost of producing of $\frac{1}{n}$ units while not being able to sell any of them. Once again, the relative profit is strictly positive.

From Cases (1), (2) and (3), we see that the experimenting firm is at least as profitable as any other firm, and so, it is imitated with positive probability. The resulting state where all firms choose state $\left(p^{c}, q^{\prime}\right)$ constitutes the new absorbing state, from which another experimentation with the quantity $q^{c}$ (which is the demand that the firms face), gives the experimenting firm a higher (relative) profit. All firms imitate this choice of quantity and the process ends up in the absorbing state where all firms choose $\left(p^{c}, q^{c}\right)$.

Second, suppose that $p>p^{n}=\beta-\frac{\tau}{2 n}$ in the initial absorbing state, so that firms do not compete for the marginal consumer. Due to our focus on transitions from market-clearing absorbing states, the demand that each firm faces (and the quantity it produces) equals $2 \frac{\beta-p}{\tau}$, 
with the corresponding expression for its profit being $2(p-c) \frac{\beta-p}{\tau}$, which is decreasing in $p$ if $p>p^{m}=\frac{\beta+c}{2}$. Because $p^{m}<p^{n}<p$ (the first inequality follows from $\tau \leq \frac{2}{3} n(\beta-c)$ ), if a firm experiments with $\left(p^{n}, q^{n}\right)$, it gets a higher profit compared to all other firms. This firm is imitated by the other firms and in the new absorbing state, and results in the (new) absorbing state being characterised by all firms choosing $\left(p^{n}, q^{n}\right)$. The transition from such an absorbing state to the state where all firms choose $\left(p^{c}, q^{c}\right)$ is possible with a series of single experimentations and has been demonstrated in the preceding paragraphs.

Part (b) Suppose we are in an absorbing state where each firms sets the price at $p^{c}$ and produces a quantity $q^{c}$. Let a firm experiment with a price $p^{\prime}$ such that it does not compete for the marginal consumer with its neighbouring firms. A necessary condition for this is $\beta-p^{c}-\frac{\tau}{n}<0$ or, equivalently, if $\tau>\frac{1}{2} n(\beta-c)$, as otherwise, the consumer located at the directly neighbouring firm would receive positive utility from the experimenting firm, precluding the possibility of segregated markets. In addition, $p^{\prime}$ has to satisfy $p^{\prime} \geq$ $2 \beta-p^{c}-\frac{\tau}{n}=2 \beta-c-\frac{2 \tau}{n}$. Then, the demand that the experimenting firm faces is $2 \frac{\beta-p}{\tau}$ and we let it choose this quantity in the experimentation. As the profit of the other firms does not change, the profit of the experimenting firm, relative to any other firm, is given by

$$
\left(p^{\prime}-c\right) 2 \frac{\beta-p^{\prime}}{\tau}-\left(p^{c}-c\right) q^{c}
$$

This relative profit is maximised at $p^{*}=\frac{\beta+c}{2}$, but this price violates the condition $p^{\prime} \geq$ $2 \beta-c-\frac{2 \tau}{n}$ (for $\tau \geq \frac{2}{3} n(\beta-c)$ ). Subject to the constraint $p^{\prime} \geq 2 \beta-c-\frac{2 \tau}{n}$, the relative profit is maximised at $p^{\prime}=2 \beta-c-\frac{2 \tau}{n}$. At this maximum, the relative profit of the experimenting firm is equal to

$$
-\frac{4}{\tau}\left(\beta-c-\frac{\tau}{n}\right)\left(\beta-c-\frac{2 \tau}{n}\right)-\frac{\tau}{n^{2}}=-\frac{4}{\tau}\left(\beta-c-\frac{3}{2} \frac{\tau}{n}\right)^{2},
$$

which is negative. From this is follows that there does not exist an experimentation with $p^{\prime} \geq 2 \beta-c-\frac{2 \tau}{n}$ that induces a transit from the initial absorbing state.

Now assume that the experimenting firm chooses a price $p^{\prime}$ such that it competes for the marginal consumer with its neighbours. This occurs when either $\tau \leq \frac{1}{2} n(\beta-c)$, or $\tau>\frac{1}{2} n(\beta-c)$ and $p^{\prime}<2 \beta-c-\frac{2 \tau}{n}$. In either case, the experimenting firm faces a demand of $\frac{p^{c}-p^{\prime}+\frac{\tau}{n}}{\tau}$. We are interested in the best case experimentation and suppose the firm experiments to set production quantity equal to the demand. By a reasoning we have used earlier, in general, the highest profit amongst all other (non-experimenting) firms will be realised by a firm that is unaffected by the experimentation. Observe that due to the low prices charged by the other firms, the experimenting firm is not able to attract consumers away from nonneighbouring firms. As, after experimentation, the profit of non-neighbouring competitors is 
at least that of the neighbouring competitors, the relative profit of the experimenting firm over the most successful non-experimenting firm is given by

$$
\left(p^{\prime}-c\right) \frac{p^{c}-p^{\prime}+\frac{\tau}{n}}{\tau}-\left(p^{c}-c\right) q^{c}
$$

This relative profit is maximised for $p^{\prime}=c+\frac{\tau}{n}\left(=p^{c}\right)$, and at this price $p^{\prime}$ (which does not represent a deviated) the relative profit is exactly zero. It follows that for any other price, the relative profit is negative. Always being less profitable then at least one firm, the experimenting firm imitates the strategy $\left(p^{c}, q^{c}\right)$, which causes the state to revert to the initial absorbing state.

The above shows that it is not possible to exit the absorbing state where all firms choose $\left(p^{c}, q^{c}\right)$ with a single experimentation while it is possible to reach it from any other absorbing state with a series of single experimentations, thereby proving the result.

\section{References}

1. Alchian A (1950). Uncertainty, evolution, and economic theory. Journal of Political Economy 58 (3): 211-221.

2. Alós-Ferrer C, A Ania and KR Schenk-Hoppé (2000). An evolutionary model of Bertrand oligopoly. Games and Economic Behavior 33 (1): 1-19.

3. Alós-Ferrer C and G Kirchsteiger (2010). General equilibrium and the emergence of (non) market clearing trading institutions. Economic Theory 44 (3): 339-360.

4. Apesteguia J, S Huck and J Oechssler (2007). Imitation: Theory and experimental evidence. Journal of Economic Theory 136 (1): 217-235.

5. Hehenkamp B and Wambach A (2010). Survival at the center - The stability of minimum differentiation. Journal of Economic Behavior and Organization 76 (3): 853-858.

6. Herings P (1997). Endogenously determined price rigidities. Economic Theory 9 (3): 471-498.

7. Huck S, HT Normann and J Oechssler (1999). Learning in Cournot oligopoly - An experiment. Economic Journal 109 (454): C80-C95.

8. Huck S, HT Normann and J Oechssler (2000). Does information about competitors actions increase or decrease competition in experimental oligopoly markets?. International Journal of Industrial Organization 18 (1): 39-57. 
9. Kandori M, GJ Mailath and R Rob (1993). Learning, mutation, and long-run equilibria in games. Econometrica 61 (1): 29-56.

10. Khan A and R Peeters (2011). Evolution of behavior when duopolists choose prices and quantities. Meteor Research Memorandum 11/027.

11. Offerman T, J Potters and J Sonnemans (2002). Imitation and belief learning in an oligopoly experiment. Review of Economic Studies 69 (4): 973-997.

12. Tirole J (1988). The Theory of Industrial Organization. MIT Press.

13. Vega-Redondo F (1997). The evolution of Walrasian behavior. Econometrica 65 (2): 275-284.

14. Young HP (1993). The evolution of conventions. Econometrica 61 (1): 57-84. 